\title{
Effects of high light stress on photosynthesis of polar macroalgae in relation to depth distribution
}

\author{
Dieter Hanelt ${ }^{1, *}$, Bettina Melchersmann ${ }^{1}$, Christian Wiencke ${ }^{1}$, Wilhelm Nultsch ${ }^{2}$ \\ ${ }^{1}$ Alfred Wegener Institute for Polar and Marine Research, D-27515 Bremerhaven, Germany \\ ${ }^{2}$ Biologische Anstalt Helgoland, Notkestr. 31, D-22067 Hamburg, Germany
}

\begin{abstract}
The capability of several polar macroalgal species to protect photosynthesis against excesslve irradiation by dynamic photoinhibition was investigated and related to the specific depth distribution of the species. Photoinhibition of photosynthesis was induced by exposure of the algae to a photon fluence rate of $500 \mu \mathrm{mol} \mathrm{m} \mathrm{s}^{-2} \mathrm{~s}^{-1}$ for $2 \mathrm{~h}$. Changes in the oxygen production rate and in vivo chlorophyll fluorescence were recorded. For oxygen measurements gross $P_{\text {mix }}$ and the slope (alpha) of the fluence rate-response curve were determined before and after photoinhibitory treatment and after recovery of photosynthesis in dim light. In fluorescence measurements the kinetics of change of the variable fluorescence during the inhibitory time phase and the recovery phase were determined. Significant differences in the reactions dunng exposure and recovery were found in the different algal classes. Withm each class a correlation between species depth distribution and the abulity to cope with high light stress was found. Algae growing in nature close to the water surface or in the intertidal were generally not severely stressed. Algae growing in the middle and upper subtidal zone showed a decrease un photosynthetic activity during high light stress with full recovery of photosynthesis in subsequent dim light. Fluorescence measurements showed that the reaction kinetics of photoinhibition and recovery were slower than in algae growing close to the water surface or in the intertidal. Algae growing in the lower subtidal also showed a decrease in the photosynthetic parameters due to high light stress; however, photosynthesis recovered only slightly and very slowly during subsequent dim light conditions. In these algae the decrease in the photosynthetic activity was caused by photodamage rather than by dynamic photoinhibition. In conclusion these experiments indicate that algae already cultured for a long time in the laboratory, retain a certain genetic adaptation to the natural light environment. This is true not only for the lower light limit, but also for the upper light limit.
\end{abstract}

KEY WORDS: Depth distribution - Fluorescence $\cdot$ High light stress - Macroalgae Oxygen production Photoinhibition Photosynthesis

\section{INTRODUCTION}

Cold water macroalgae show a pronounced ability to tolerate dark periods of up to $1 \mathrm{yr}$ without suffering damage (Wiencke 1988, 1990a). Moreover, the light requirements for completion of the life-cycle, especially of Antarctic species, are very low (Wiencke 1990a, b). The endemic Antarctic species Himantothallus grandifolius and Desmarestia anceps require an annual light dose of only $31 \mathrm{~mol}$ photons $\mathrm{m}^{-2}$ for their existence, a value lower than in the endemic Arctic Laminaria solidungula and the cold temperate L. hyperborea,

\footnotetext{
•E-mail: dhanelt@awi-bremerhaven.de
}

which need $49 \mathrm{~mol}$ photons $\mathrm{m}^{-2}$ (Chapman \& Lindley 1980) or $71 \mathrm{~mol}$ photons $\mathrm{m}^{-2}$ (Lüning \& Dring 1979), respectively. These low light demands for completion of the life-cycle of polar species are reflected in their light demands for growth. Microthalli and juvenile macrothalli of Antarctic brown algae are able to grow at very low photon fluence rates and growth is lightsaturated at 4 to $12 \mu \mathrm{mol}$ photons $\mathrm{m}^{-2} \mathrm{~s}^{-1}$ (Wiencke 1990a). In young sporophytes of Antarctic Desmarestiales (5 to $8 \mathrm{~cm}$ long) growth is light-saturated between 15 and $20 \mathrm{\mu mol}$ photons $\mathrm{m}^{-2} \mathrm{~s}^{-1}$, irrespective of the cultivation temperature (Wiencke \& Fischer 1990). These values are in the same range as or even lower than for microthalli (Kain 1969, Lüning \& Neushul 1978) and macrothalli (Kain 1969, Fortes \& Lüning 
1980) of Laminariales from other regions. A further characteristic is the decrease of growth rate at higher photon fluence rates of about $80 \mu \mathrm{mol} \mathrm{m} \mathrm{m}^{-2} \mathrm{~s}^{-1}$ in the endemic Antarctic $H$. grandifolius and $D$. anceps. In contrast, the endemic Arctic L. solidungula and the Arctic-cold temperate L. digitata and $L$. saccharina do not show inhibition of growth at this irradiance (Fortes \& Lüning 1980, Wiencke \& Fischer 1990).

Interestingly, polar algae are not only adapted to low light conditions but also can cope with very high photon fluence rates in summer due to their ability to undergo dynamic photoinhibition, a photoprotective mechanism by which excessive absorbed energy is rendered harmless by thermal dissipation (Krause \& Weis 1991, Osmond 1994). The intertidal brown alga Adenocystis utricularis and the red alga Palmaria decipiens from the lower intertidal and upper subtidal become photoinhibited in response to an increase of solar irradiance during low tide (Hanelt et al. 1994, Hanelt 1996). The reaction of photoinihibition and recovery in $A$. utricularis was faster than in species from the tropical and Arctic-temperate regions (Hanelt 1992, Hanelt et al. 1994, Hanelt \& Nultsch 1995), indicating a strong temperature adaptation of the enzymatic processes involved during recovery. The capability for dynamic photoinhibition during exposure to high light conditions as well as the general degree of adaptation of photosynthesis of individual species to different light regimes may influence the upper depth distribution of algae (Hanelt 1996).

Recently, it was shown that the ability to acclimate to temporary high light conditions increases with the age of the thallus (Hanelt et al. 1997a). In particular, it was shown that gametophytes and older sporophytes of Laminaria saccharina acclimate more quickly to high light conditions than the juvenile and young sporophytes. Photosynthesis in adult sporophytes and gametophytes is inhibited more rapidly than in young sporophytes, i.e. emission of excitation energy as harmless thermal radiation in photosystem II is inducing more rapidly and more strongly. Similarly, recovery is also faster in comparison to juveniles, i.e. photosynthetic efficiency is restored more quickly in gametophytes and older sporophytes. Therefore, in the natural environment the canopy can shelter juvenile algal stages against negative effects of higher irradiances. Older plants as canopy-plants have established photoprotective mechanisms and can cope with excessive irradiance.

Algae growing in the upper subtidal clearly show a higher tolerance to higher solar radiation and, especially, UV-stress than algae collected from deeper zones (Drew 1974, Larkum \& Wood 1993, Dring et al. 1996, Hanelt et al. 1997b). In this study, we tested the hypothesis that the upper limit of occurrence of algae on the shore depends to a certain extent on the photoprotective capability 0 : the individual. The genetic adaptation of several taxa and life history stages of inter- and subtidal polar algae was examined with respect to their response to temporary moderate high light stress. Physiological response was measured as oxygen production and in vivo chlorophyll fluorescence. Both methods have already been proved to give reliable results in many marine macroalgae (Hanelt et al. 1995, Hanelt 1996).

\section{MATERIAL AND METHODS}

The species were isolated using the methods described by Clayton \& Wiencke (1986) at the locations given in Table 1. Occurrence of species was related to the upper sublittoral, a zone from $1 \mathrm{~m}$ to a few meters below mean low water, the middle sublittoral and the lower sublittoral (dim light zone) with a transmittance lower than 5\% (according to Lüning 1990). In summer, with clear water conditions, a light transmittance of about $75 \%\left(\approx 1100 \mu \mathrm{mol} \mathrm{m} \mathrm{m}^{-2} \mathrm{~s}^{-1}, 3 \mathrm{~m}\right.$ depth) was determined in Fildes Bay (King George Island, Antartica) and of about $50 \%\left(\approx 500 \mu \mathrm{mol} \mathrm{m} \mathrm{m}^{-2} \mathrm{~s}^{-1}\right)$ in Kongsfjord (Spitsbergen, Arctic) (Hanelt et al. 1994, 1997a) in the transition from the upper to the middle sublittoral zone.

For culture, sterile North Sea water was enriched with nutrients after Provasoll (Starr \& Zeikus 1987). The general culture conditions were described by Wiencke \& tom Dieck (1989). Microthalli were maintained in the laboratory at 0 to $5^{\circ} \mathrm{C}$ in Petri dishes in about 3 to $5 \mu \mathrm{mol} \mathrm{m} \mathrm{m}^{-2} \mathrm{~s}^{-1}$. For induction of fertility vegetative thalli of gametophytes/conchocelis were gently crushed with pestle and mortar and after fertilisation or release of conchospores, developing macrothalli were transferred to higher fluence rates $\left(-10 \mu \mathrm{mol} \mathrm{m}{ }^{-2} \mathrm{~s}^{-1}\right)$ in aerated glass beakers. For growth the algae were illuminated with about $10 \mu \mathrm{mol} \mathrm{m}^{-2} \mathrm{~s}^{-1}$ by fluorescent tubes (L58/12W daylight, Osram) in a light:dark cycle of 16:8 h. Larger sporophytes, raised from microthalli or spores, were cultured in about 51 of medium, which was changed weekly. The nonAntarctic species Laminaria saccharina and Desmarestia mülleri were grown at $10^{\circ} \mathrm{C}$, whereas all other algae were cultured at $0^{\circ} \mathrm{C}$ in constant-temperature rooms. Species cultured for several years were grown for at least 1 mo in new conditions prior to the experiments to ensure acclima:ion.

Oxygen measurements. The oxygen production rate of small thalli or pieces cut out of larger thalli was measured with a temperature-compensated Clark electrode (Oxi 92,WTW, Germany) at a water temperature of 0 or $10^{\circ} \mathrm{C}$ in a closed oxygen measuring system, described in detail by Huppertz et al. (1990) and Hanelt 
Table 1 Methods of investigation and natural occurrence of the investigated Antarctic algae according to Kloser et al. $(1994,1996)$ and own observations. Classification of littoral zones according to Lüning (1990)

\begin{tabular}{|c|c|c|c|}
\hline Species & Sampling site & Depth distribution & Methods used \\
\hline \multicolumn{4}{|l|}{ Chlorophyta } \\
\hline Urospora penicilliformis (Roth) Areschoug & Kung George Island (South Shetlands) & Upper intertıdal & Oxygen \\
\hline Enteromorpha bulbosa (Suhr) Montagne & King George Island (South Shetlands) & Intertidal & Oxygen \\
\hline Acrosiphonia arcta (Dillw.) Agardh & Kıng Ceorge Island (South Shetlands) & Intertidal & Oxygen \\
\hline Lambia antarctica (Skottsberg) Delepine & King George Island (South Shetlands) & Subtidal & Oxygen \\
\hline \multicolumn{4}{|l|}{ Phaeophyta } \\
\hline Adenocystis utricularis Bory & King George Island (South Shetlands) & Intertidal & Fluorescence \\
\hline Laminaria saccharina (L.) Lamour & Kongsfjord (Spitsbergen) & Upper-lower subtidal & Fluorescence \\
\hline Desmarestia mulleri Ramirez et Peters & Strait of Magellan (South Chile) & Upper subtidal & Fluorescence \\
\hline Desmarestia antarctica Moe et Silva & King George Island (South Shetlands) & Upper-muddle subtidal & Oxygen/Fluorescence \\
\hline Desmarestia anceps Montagne & King George Island (South Shetlands) & Upper-lower subtidal & Oxygen \\
\hline \multirow{2}{*}{$\begin{array}{l}\text { Ascoseira mirabilis Skottsberg } \\
\text { Himantothallus grandifolius } \\
\text { (A. \& E.S.Gepp) Zinova }\end{array}$} & Kung George Island (South Shetlands) & Upper-middle subtidal & Oxygen/Fluorescence \\
\hline & King George Island (South Shetlands) & Middle-lower subtidal & Oxygen/Fluorescence \\
\hline \multicolumn{4}{|l|}{ Rhodophyta } \\
\hline $\begin{array}{l}\text { Porphyra endiviifolium } \\
\text { (A.\& E.S. Gepp) Chamberlain }\end{array}$ & King George Island (South Shetlands) & Upper intertidal & Oxygen/Fluorescence \\
\hline Indaea cordata (Turn.) Bory & King George Island (South Shetlands) & Upper subtidal & Fluorescence \\
\hline Gymnogongrus antarcticus Skottsberg & Kung George Island (South Shetlands) & Upper-lower subtidal & Fluorescence \\
\hline Myriogramme mangins (Gain) Skottsberg & King George Island (South Shetlands) & Middle subtidal & Fluorescence \\
\hline $\begin{array}{l}\text { Gigartina skottsbergii (Bory) } \\
\text { Setchell et Gardner }\end{array}$ & King George Island (South Shetlands) & Middle (lower) subtidal & Fluorescence \\
\hline Delesseria lancifiolia (Hooker) Agardh & King George Island (South Shetlands) & Middle-lower subtıdal & Oxygen/Fluorescence \\
\hline Plocamium cartilagineum (L.) Dixon & King George Island (South Shetlands) & Middle-lower subtıdal & Fluorescence \\
\hline Phycodrys austrogeorgica Skottsberg & King George Island (South Shetlands) & Middle-lower subtidal & Oxygen \\
\hline Pantoneura plocamioides Kylin & King George Island (South Shetlands) & Middle-lower subtıdal & Oxygen/Fluorescence \\
\hline
\end{tabular}

(1992). A piece of thallus was transferred into the oxygen cuvette, fixed between 2 perforated Plexiglas discs close to the membrane of the electrode and exposed to light emitted by a halogen lamp (Xenophot, Osram) in a projector. Photon irradiances were adjusted by use of glass neutral density filters (Schott. Germany) and measured using a quantum sensor (Li189, Li-Cor, USA). Culture medium was enriched with $4 \mathrm{mM}$ sodium bicarbonate and proton concentration was adjusted to $\mathrm{pH}$ 8. Thus, carbon limitation in the incubation chamber, which could already cause photoinhibition at low irradiances, was avoided. Before the oxygen measurements, the oxygen concentration of the medium was lowered to $50 \%$ of the saturation level by flushing with gaseous nitrogen. After a preceding dark period of $20 \mathrm{~min}$ to measure respiration rate, the samples were exposed to several fluences, each for $10 \mathrm{~min}$, in order to obtain a constant rate of photosynthetic oxygen production. After measuring the fluence rateresponse curve, the medium in the cuvette was exchanged with fresh medium with low oxygen content. Subsequently, the alga was irradiated with $500 \mu \mathrm{mol}$ $\mathrm{m}^{-2} \mathrm{~s}^{-1}$ white light for $2 \mathrm{~h}$. This is about one-third of the maximal irradiance incident on the water surface in the region of King George Island, and was high enough to induce photoinhibition in all species without inducing strong photodamage. The respective underwater light conditions in the Arctic and Antarctic are de- scribed by Hanelt et al. $(1994,1997$ a) and Klöser et al. (1993). Directly after the high light irradiation, the medium in the cuvette was exchanged again and a second fluence rate-response curve was recorded. Then, the algal sample was exposed for 14 to $16 \mathrm{~h}$ to about $10 \mu \mathrm{mol} \mathrm{m} \mathrm{m}^{-2} \mathrm{~s}^{-1}$ white light in fresh medium for recovery of photosynthesis. After the recovery phase a third fluence rate-response curve was recorded in fresh medium. At the end of the experiment the thalli were carefully blotted with soft paper tissue and fresh weight was determined. Oxygen production rates were related as a percentage of the respective control values to compare the changes in the shape of the fluence rate-response curves of different species. Alpha ( $\alpha$, the initial slope of the P-I curve) was calculated using linear regression. All data of the light limited part of the $P$ - $I$ curves which show no deviation from a linear increase $\left(r^{2}>0.9\right)$ were used. $P_{\text {max }}$ values were calculated using a parallel to the abscissa intersecting the maximal photosynthetic rates. Experiments were replicated at least 3 times (total $n=4$ ) for each species.

Fluorescence measurements. In vivo chlorophyll fluorescence was measured with a pulse-amplitude modulation fluorometer (PAM 2000, Walz, Effeltrich, Germany) connected to a personal computer. The system is based on the principle devised by Schreiber et al. (1986). The ratio of variable to maximal fluorescence $F_{v} / F_{\mathrm{m}}$ of the dark-adapted plants was used as a 
measure of photoinhibition (cf. Krause \& Weis 1991). $F_{\mathrm{v}}=F_{\mathrm{m}}-F_{0}$, in which $F_{0}$ is the initial fluorescence, i.e. when all reaction centres of PS II are active or 'open', and $F_{m}$ is the maximal fluorescence determined under strong light, i.e. when all PS Il centres are 'closed'. Earlier experiments have shown that the results of fluorescence measurements were consistent with those of oxygen measurements and that $F_{\mathrm{v}} / F_{\mathrm{m}}$ is a good measure of photosynthetic efficiency (Hanelt 1992, Hanelt et al. 1995). Thallus pieces were mounted at a distance of $3 \mathrm{~mm}$ from the end of the fiber optic probe of the fluorometer and exposed to darkness in a custom made seawater cuvette at 0 or in some cases at $10^{\circ} \mathrm{C}$. Tufts of gametophytes were spread out in a thin cellular layer on a small net which was fixed at the end of the fiberoptic probe. After application of a $5 \mathrm{~s}$ far-red pulse $\left(-30 \mu \mathrm{mol} \mathrm{m}{ }^{-2} \mathrm{~s}^{-1}, 735 \mathrm{~nm}\right)$ used to oxidise the electron transport chain, the brown algae were darkened for 5 min. Then, $F_{0}$ was measured with red measuring light pulses $\left(-0.3 \mu \mathrm{mol} \mathrm{m} \mathrm{m}^{-2} \mathrm{~s}^{-1}, 650 \mathrm{~nm}\right)$ and $F_{\mathrm{m}}$ was determined with a $600 \mathrm{~ms}$ completely saturating white light pulse $\left(\sim 9200 \mu \mathrm{mol} \mathrm{m} \mathrm{m}^{-2} \mathrm{~s}^{-1}\right)$. Subsequently, this sequence was repeated twice and the mean values of $F_{0}$ and $F_{\mathrm{m}}$ were calculated from 3 measurements. Then, the samples were exposed to $500 \mu \mathrm{mol} \mathrm{m} \mathrm{m}^{-2} \mathrm{~s}^{-1}$ white light produced by a halogen lamp (Osram Xenophot $150 \mathrm{~W})$ for $2 \mathrm{~h}$ and, after that, to $10 \mu \mathrm{mol} \mathrm{m} \mathrm{m}^{-2} \mathrm{~s}^{-1}$ to allow photosynthesis to recover for several hours. During the inhibition and recovery period photosynthetic efficiency of the sample was measured every 30 min by the fluorescence method described above. No significant recovery was observed in the plants during the short dark periods necessary for the fluorescence measurements, as determined during 3 consecutive $F_{v} / F_{m}$ measurements. In red algae the method was changed slightly. After application of a $5 \mathrm{~s}$ far-red pulse $\left(\sim 30 \mu \mathrm{mol} \mathrm{m}^{-2} \mathrm{~s}^{-1}\right)$ the red algal sample was darkened. A short red actinic pulse $\left(5 \mathrm{~s}, 8 \mu \mathrm{mol} \mathrm{m} \mathrm{m}^{-2} \mathrm{~s}^{-1}\right.$, $655 \mathrm{~nm}$ ) was given after 5 min of darkness to ensure a stabilised fluorescence emission during the following $F_{\mathrm{m}}$ measurement. In red algae this pulse especially exites photosystem I and the onset of the $F_{n}$ decline during a saturation pulse is delayed. Subsequently, a 5 s far-red pulse was given again to fully oxidise the electron transport chain. Then $F_{0}$ was measured with a pulsed, red measuring light $\left(\sim 0.3 \mu \mathrm{mol} \mathrm{m} \mathrm{m}^{-2} \mathrm{~s}^{-1}, 650 \mathrm{~nm}\right)$ and $F_{\mathrm{m}}$ was determined with a $400 \mathrm{~ms}$ completely saturating white light pulse $\left(-9200 \mu \mathrm{mol} \mathrm{m} \mathrm{m}^{-2} \mathrm{~s}^{-1}\right)$. This sequence was repeated twice $(n=3)$ with an intermediate dark period of $5 \mathrm{~min}$ to control possible changes of the fluorescence parameter by incomplete recovery of fluorescence quenching parameters (e.g. energy quenching qE or quenching by state transitions qT). Each experiment with one species was repeated at least twice with different individuals. Inhibition of photosynthesis was calculated by the formula:

$$
\text { Inhibition }(\%)=100-100 \cdot \frac{F_{\mathrm{v}} / F_{\mathrm{m}} \text { during exposure }}{F_{\mathrm{v}} / F_{\mathrm{m}} \text { of control }}
$$

Statistical comparison between the different algal classes and between the species of each class was made by a 1 -way analysis of variance (ANOVA) and Fisher's protected least significant difference (Fishers PLSD) or with a 2-tailed $t$-test within the experimental time course of one species. Statistically significant differences were observed if the p-value was $\leq 0.05$ (significance level $5 \%$ ).

\section{RESULTS}

\section{Oxygen measurements}

Fluence rate-response curves of photosynthetic oxygen production ( $P$ - $I$ curves), measured before and after photoinhibitory treatment with relatively strong white light, showed a general decrease in photosynthetic capacity and efficiency in most of the investigated species. The P-I curves of Lambia antartica are shown as a typical example to demonstrate these changes of the photosynthetic capacity (Fig. 1A) and efficiency (Fig. 1B) due to high light stress. After a recovery period of several hours in dim white light both photosynthetic parameters increased again, indicating a more efficient use of light energy in photochemistry. In $L$. antartica the respiration rate increased after recovery, hence causing a decrease in net $P_{\max }$ (Fig. 1). However, gross $P_{\max }$ (indicating photosynthetic capacity) attained the same value as the control. Changes of gross $P_{\max }$ or of $\alpha$, induced by a temporary high irradiance, were compared among all species.

The subtidal Lambia antartica showed a significant decrease in the photosynthetic capacity due to photoinhibition in comparison to the 3 other green algal species from the intertidal which exhibited almost no change (Fig. 2A). After recovery all green algal species showed a significant increase of $P_{\max }$ in Acrosiphonia arcta and Urospora penicilliformis $P_{\max }$ exceeded the control value. In principle the same was observed with respect to $\alpha$ (Fig. 2B). The decrease of $\alpha$ during photoinhibition was higher in $L$. antarctica than in $A$. arcta or Enteromorpha bulbosa. No significant decrease in $\alpha$ was found in $U$. penicilliformis. After recovery, $\alpha$ was considerably above the control values in all species.

The red algae Pantoneura plocamioides, Delesseria lancifolia and Phycodrys austrogeorgica, from the subtidal, and Porphyra endiviifolium from the upper intertidal zone are compared in Fig. 3. After high light stress $P$. plocamioides and $P$. endivifolium showed only minor changes of photosynthetic capacity com- 


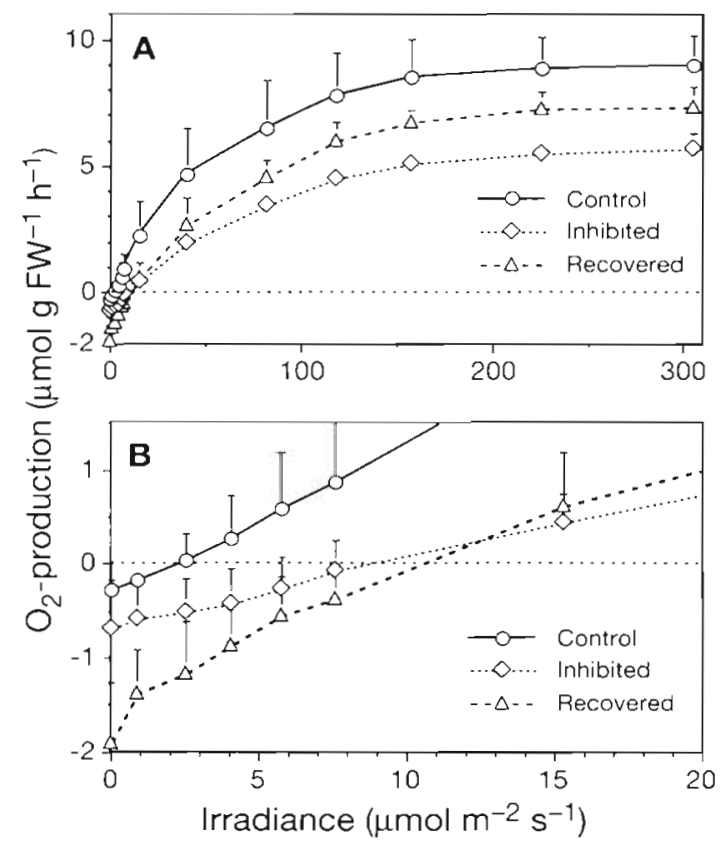

Fig. 1. Lambia antartica. Fluence rate-response curve of photosynthetic oxygen production in the green alga. (A) Change of the photosynthetic capacity, (B) change of the photosynthetic efficiency and respiration rate. Shown are: control curve; curve after $2 \mathrm{~h}$ exposure to $500 \mu \mathrm{mol} \mathrm{m}-2 \mathrm{~s}^{-1}$ ('inhibited'); and

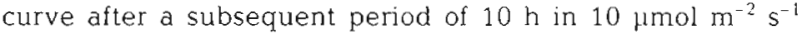

('Recovered') ( $n=4$, mean value \pm standard deviation)

pared to $D$. lancifolia and $P$. austrogeorgica, which exhibited a significant decrease of $P_{\max }$ (Fig. 3A). In contrast, photosynthetic efficiency decreased significantly in all investigated red algal species (Fig 3B). Recovery after the subsequent dim light period was observed in all red algae, especially in $P$. endiviifolium. This alga showed a higher photosynthetic capacity and efficiency than the control due to high light activation. In contrast, in $D$. lancifolia and $P$. austrogeorgica neither $P_{\max }$ nor $\alpha$ fully recovered. High individual variability in $P$. plocamioides caused differences between recovery and control values to be not statistically significant.

The brown alga Himantothallus grandifolius grows only in the mid to lower subtidal, and Ascoseira mirabilis in the middle and upper zone, whereas both Desmarestia species are more abundant in the upper part of the subtidal. Fig. 4 shows that the decrease of photosynthesis $\left(P_{\max }\right.$ and $\alpha$ ) caused by photoinhibition becomes smaller according to this order. No significant recovery after the dim light period was observed in $A$. mirabilis, and photosynthesis of $H$. grandifolius recovered only slightly. In contrast, $D$. antarctica recovered fully and in $D$. anceps
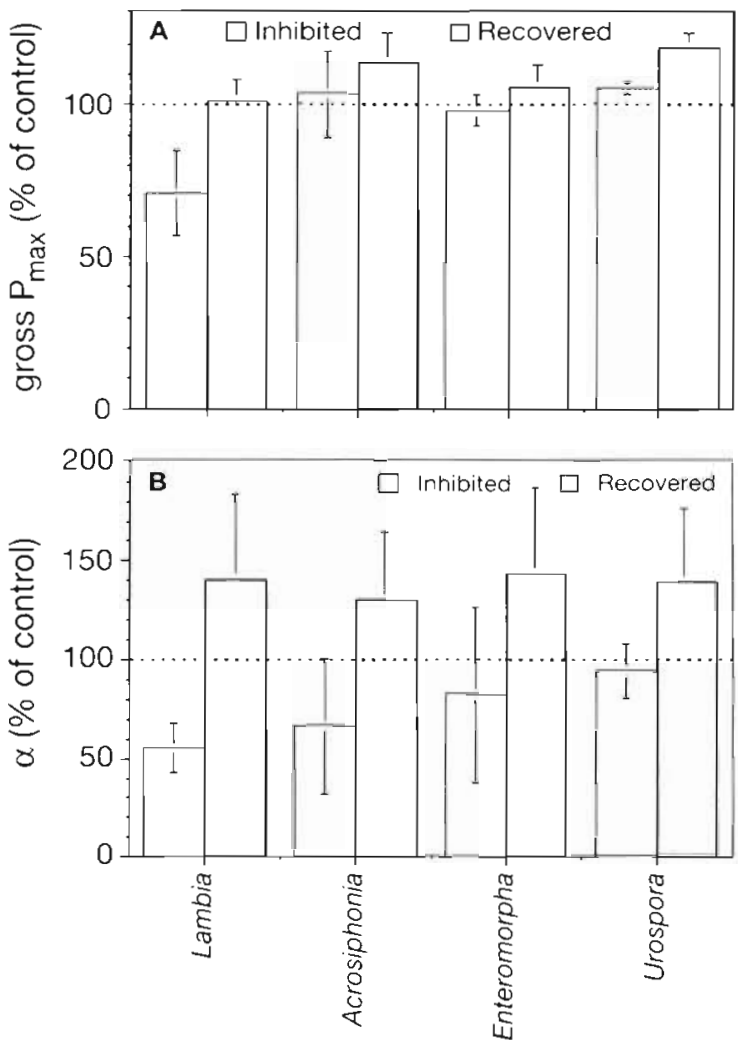

Fig. 2. Changes of photosynthetic parameters after high light exposure of $500 \mu \mathrm{mol} \mathrm{m} \mathrm{m}^{-2} \mathrm{~s}^{-1}$ for $2 \mathrm{~h}$ and after recovery in $10 \mu \mathrm{mol} \mathrm{m} \mathrm{m}^{-2} \mathrm{~s}^{-1}$ in several green algal species. (A) Changes in photosynthetic capacity, (B) changes in photosynthetic efficiency $(n=3$, mean value \pm standard deviation)

the $P_{\max }$ and $\alpha$ values exceeded the control values. A comparison between the brown algal species shows that the relative photosynthetic parameters of $A$. mirabilis and $H$. grandifolius are not significantly different.

After an irradiation of $2 \mathrm{~h}$ with $500 \mu \mathrm{mol} \mathrm{m}^{-2} \mathrm{~s}^{-1}$ white light, the decrease of photosynthetic capacity in the green algae was significantly different from the brown

Table 2. Changes of photosynthetic parameters during and after exposure to high light stress determined by oxygen production. (Means $\pm \mathrm{SD}$ in percent of contral, 'significantly different $(p<0.05)$ by use of Fisher's PLSD, ANOVA table shown below)

\begin{tabular}{|c|c|c|c|c|c|c|c|c|c|}
\hline \multirow{3}{*}{$\begin{array}{l}\text { Algal } \\
\text { Class }\end{array}$} & \multirow[t]{3}{*}{ Count } & \multicolumn{4}{|c|}{ Inhibition } & \multicolumn{4}{|c|}{ Recovery } \\
\hline & & \multicolumn{2}{|c|}{ Gross $P_{\mathrm{ma \lambda}}$} & \multicolumn{2}{|c|}{$\alpha$} & \multicolumn{2}{|c|}{ Gross $P_{\max }$} & \multicolumn{2}{|c|}{$\alpha$} \\
\hline & & Mean & $\mathrm{SD}$ & Mean & $\mathrm{SD}$ & Mean & $\mathrm{SD}$ & Mean & $\mathrm{SD}$ \\
\hline Brown & 18 & 80.1 & 15.4 & $48.1^{\circ}$ & 24.3 & $92.8^{\circ}$ & 20.5 & 90.9 & 51.5 \\
\hline Green & 16 & $93.9^{\circ}$ & 17.1 & 73.9 & 30.4 & 109.9 & 9.5 & $138.2^{\circ}$ & 35.4 \\
\hline Red & 16 & 77.7 & 24.7 & 63.7 & 20.5 & 98.7 & 23.3 & 101.4 & 30.5 \\
\hline \multicolumn{2}{|l|}{ Parameter } & \multicolumn{2}{|c|}{ df (groups/error) } & \multicolumn{2}{|c|}{ Mean square } & \multicolumn{2}{|r|}{$F$} & & $\mathrm{p}$ \\
\hline \multicolumn{2}{|l|}{$\alpha(\operatorname{Inh})}$. & \multicolumn{2}{|l|}{$2 / 47$} & \multicolumn{2}{|r|}{2902} & \multicolumn{2}{|r|}{4.499} & \multicolumn{2}{|c|}{0.0163} \\
\hline \multirow{2}{*}{\multicolumn{2}{|c|}{$P_{\text {rnax }}($ Inh. $)$}} & \multicolumn{2}{|l|}{$2 / 47$} & \multicolumn{2}{|r|}{1246} & \multicolumn{2}{|r|}{3.324} & \multicolumn{2}{|c|}{0.0446} \\
\hline \multirow{2}{*}{\multicolumn{2}{|c|}{$\begin{array}{l}\alpha(\text { Rec. }) \\
P_{\max }(\text { Rec.) }\end{array}$}} & \multirow{2}{*}{\multicolumn{2}{|c|}{$\begin{array}{l}2 / 47 \\
2 / 47\end{array}$}} & \multicolumn{2}{|r|}{10244} & \multicolumn{2}{|r|}{6.176} & \multicolumn{2}{|c|}{0.0042} \\
\hline & & & & \multicolumn{2}{|r|}{1262} & \multicolumn{2}{|r|}{3.562} & \multicolumn{2}{|c|}{0.0363} \\
\hline
\end{tabular}



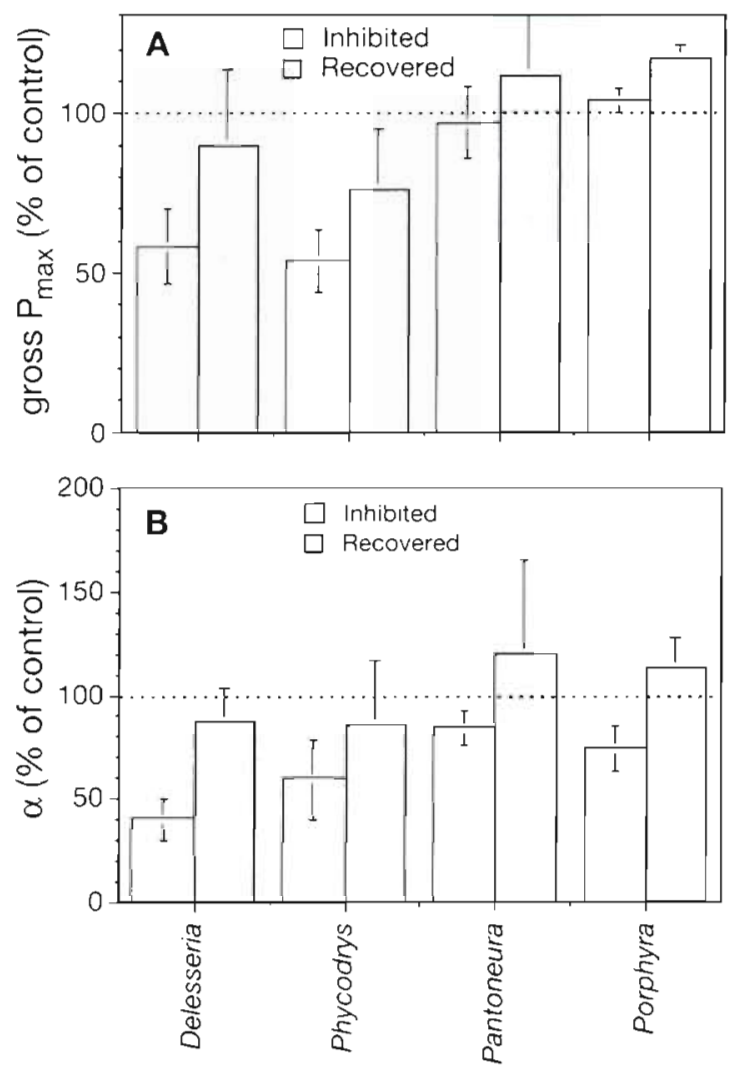

Fig. 3. Changes of photosynthetic parameters, as shown in Fig. 2, for several red algal species

and red algae (Table 2 ). $P_{\max }$ decreased only slightly in the green algae $(6 \%)$, but by about $20 \%$ in the brown and red algae. A significantly different decrease of $\alpha$ was observed in the studied brown compared to green and red algae, with a decrease of $\alpha$ in green algae of about $26 \%$, in red algae about $36 \%$ and in the brown algae about $52 \%$ (Table 2). Statistically significant differences were also found in the recovery rate between the different algal classes, especially in the fluorescence parameters. Thus, the comparisons of algae growing in different littoral zones in the natural habitat were done within each algal class.

\section{Fluorescence measurements}

In addition to the oxygen measurements, changes of in vivo fluorescence were measured in different taxa and life history stages of the brown and red algae. Figs. $5 \& 6$ show experimental time courses of changes in the potential quantum yield of photosynthesis $\left(F_{\mathrm{v}} / F_{\mathrm{m}}\right)$. At first the inhibition rate increased rapidly and then slowly approached a saturation level during the exposure of $500 \mu \mathrm{mol} \mathrm{m}{ }^{-2} \mathrm{~s}^{-1}$, indicating a 1st order reaction. In Adenocystis utricularis and Porphyra
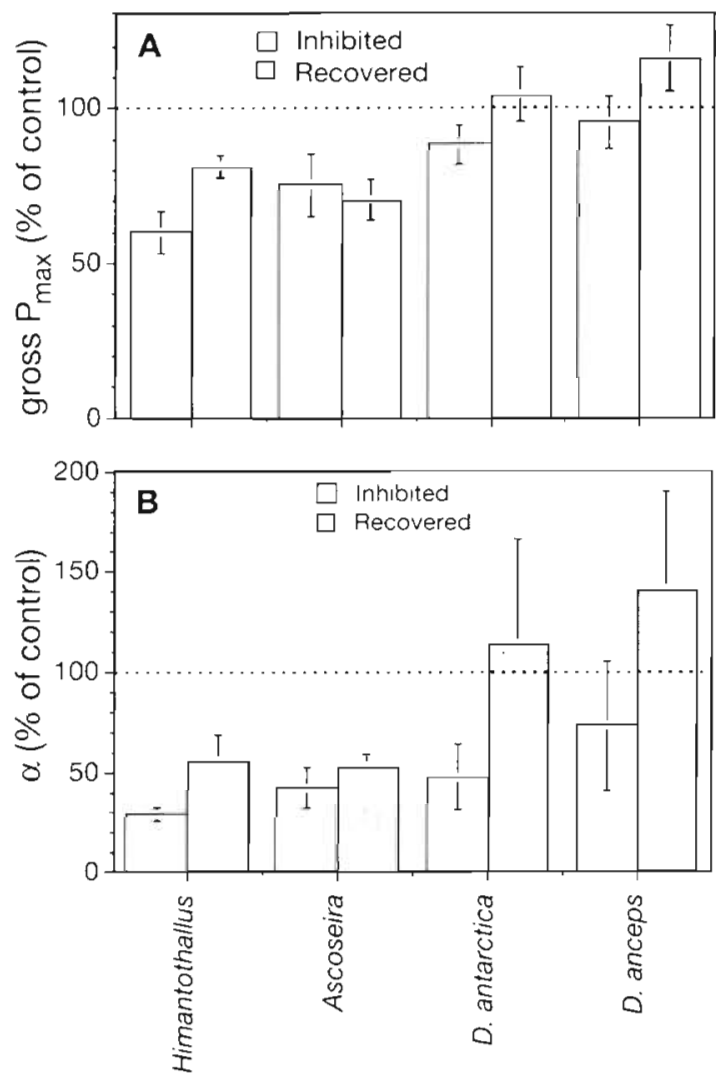

Fig. 4. Changes of photosynthetic parameters, as shown in Fig. 2 for several brown algal species

endivifolium recovery began with a fast kinetics and ended with a slower kinetics. A comparison between the brown subtidal alga Himantothallus grandifolius and the brown intertidal alga $A$. utricularis shows that the intertidal alga reacts much faster than the subtidal one (Fig. 5). This means that, with a faster acclimation, the saturation level of inhibition was reached earlier so that the curve for the period $30 \mathrm{~min}$ to $2 \mathrm{~h}$ became flatter and, hence, the slope of a fitted logarithmic curve was lower (Fig. 5). In contrast, the slope becomes more negative with a faster reaction in the first recovery phase. This applies also to the 2 red algal species from the subtidal and intertidal (Fig. 6). Thus, the data measured during the inhibition phase could always be fitted to the logarithmic equation $(y=m$ $\left.\log (x)+b_{i} r^{2}>0.97\right)$ shown by the regression lines in the figures. For mathematical reasons the value for $x=0$ cannot be included into the calculations. The inhibition level decreased after the subsequent exposure to dim light of $10 \mu \mathrm{mol} \mathrm{m} \mathrm{m}^{-2} \mathrm{~s}^{-1}$. Also the data during the recovery period (time $>2 \mathrm{~h}$ ) in Figs. $5 \mathrm{~A} \& 6 \mathrm{~A}$ show a very good fit to the logarithmic equation (dashed line, $\mathrm{r}^{2}>0.98$ ), indicating here too a reaction of 1 st order. However, in algae which showed a very fast rate of recovery, this type of curve fits more or less only 

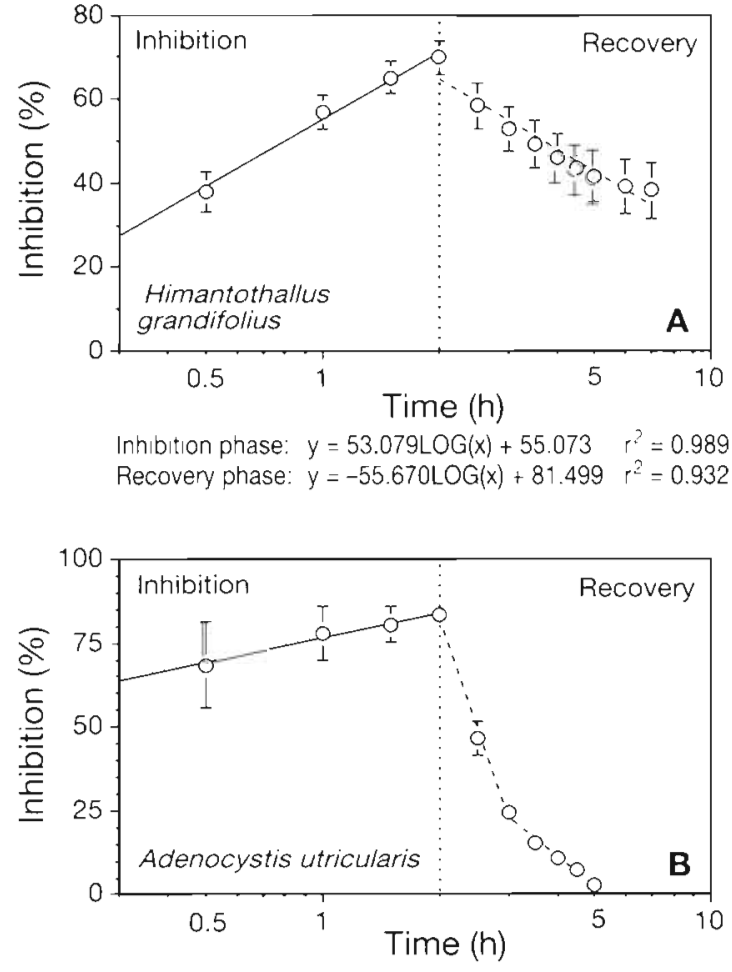

Inhibition phase: $\quad y=24.441 \operatorname{LOG}(x)+76.524 \quad r^{2}=0.977$ 1st Recovery phase: $y=-337.175 \mathrm{LOG}(x)+183.593 r^{2}=0.993$ 2nd Recovery phase: $y=-93.925 \operatorname{LOG}(x)+68.015 \quad r^{2}=0.985$

Fig. 5. Himantothallus grandifolius, Adenocystis utricularis. Photoinhibition and recovery in 2 brown algal species. The thalli were first exposed to high light $\left(500 \mu \mathrm{mol} \mathrm{m} \mathrm{m}^{-2} \mathrm{~s}^{-1}, 2 \mathrm{~h}\right)$ and subsequently to dim white light $\left(10 \mu \mathrm{mol} \mathrm{m} \mathrm{m}^{-2} \mathrm{~s}^{-1}\right)$. (A) Time course of $H$. grandifolius growing in the lower subtidal zone. (B) Time course of A. utricularis growing in shallow water and in the intertidal zone. Inhibition was calculated as the decrease in percent of the $F_{\mathrm{v}} / F_{\mathrm{m}}$ value of non-photoinhibited algae $\left(F_{v} / F_{\mathrm{m}}\right.$ of control: $\mathrm{A}, 0.706 ; \mathrm{B}, 0.711 ; \mathrm{n}=4$, mean value \pm standard deviation). Curves were calculated by non-linear regression analysis $(y=m \log (x)+b)$; equation and coefficient of determination are shown for each phase. Note logarithmic abscissa

to the initial part of the recovery period (Figs. 5B \& 6B, $r^{2}>0.89$ ). After $1.5 \mathrm{~h}$ of recovery the data can be fit well to a second equation, indicating that 2 different processes are involved in recovery of photosynthesis and, hence, recovery is clearly biphasic. Generally, the slope $(m)$ was a good indicator of the response of the algae to changes in the light environment. Therefore, the parameters $m_{1 n h}$ for the photoinhibitory process and $m_{\text {rec }}$ for the recovery process were compared among the investigated species (Figs. 7 to 10).

The slopes of the regression lines in relation to the depth distribution of the algae are shown for the red algae in Figs. $7 \& 8$ and for brown algae in Figs. $9 \& 10$. Red algae show a lower inhibitory rate and significantly much slower recovery kinetics than brown algae. Therefore, a statistical comparison among the

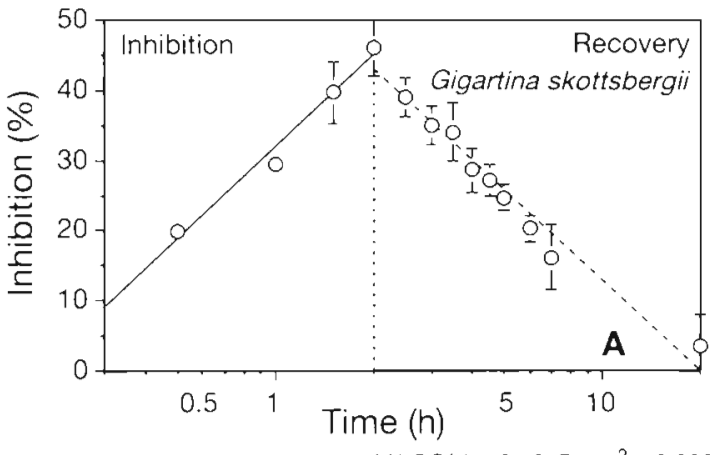

Inhibition phase: $y=43.560 \operatorname{LOG}(x)+31.847 \quad r^{2}=0.980$

Recovery phase: $y=-42.787 \operatorname{LOG}(x)+55.676 r^{2}=0.967$

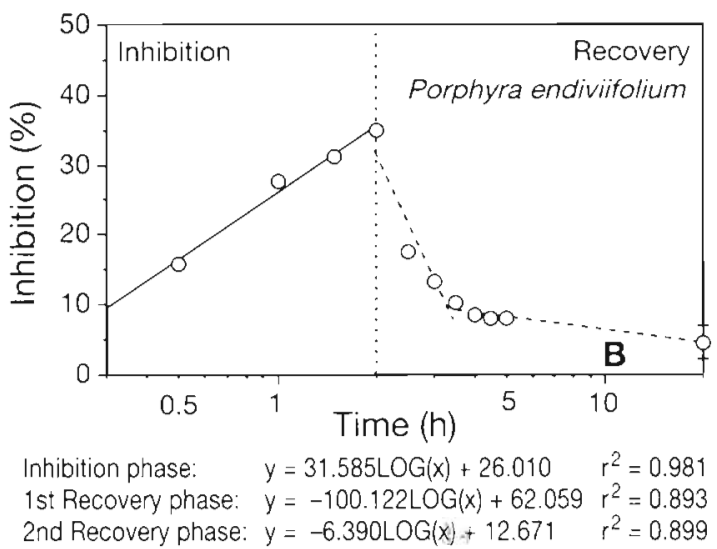

Fig. 6. Gigartina skottsbergii, Porphyra endivifolium. Photoinhibition and recovery for 2 red algal species (details as in Fig. 5). (A) Time course of $G$. skottsbergu growing in the middle-lower subtidal zone (control $F_{1} / F_{m}=0.66$ ). (B) Time course of $P$. endivifolium growing in shallow waters and in the intertidal zone (control: $F_{v} / F_{\mathrm{m}}=0.675$ )

species was made within the respective algal class. A lower value of $m_{\text {inh }}$ means that the maximal reaction of photoinhibition was reached earlier. For statistical treatment the algae were differentiated into 3 groups: Pantoneura plocamioides, Plocamium cartilagineum and Delesseria lancifolia for the lower subtidal, Gigartina skottsbergii and Myriogramme mangini for the middle subtidal and Gymnogongrus antarcticus, Iridaea cordata and Porphyra endivifolium for the upper subtidal or intertidal zone. In Fig 7 no significant difference was observed between the inhibition rates of the red algae in relation to their depth distribution (ANOVA, $d f=2,25, M S=38.2, F=0.404, p=0.673$ ). In addition, $I$. cordata cultured at either 10 or at $100 \mu \mathrm{mol}$ $\mathrm{m}^{-2} \mathrm{~s}^{-1}$ showed no difference in the reaction kinetics. The conchocelis life stage of $P$. endiviifolium, which lives in the field under very low light conditions in limestone and, thus, was cultured at only about 2 umol $\mathrm{m}^{-2} \mathrm{~s}^{-1}$, was inhibited much faster than its gametophyte. In contrast, investigation of the recovery kinetics show a different result. Red algae growing higher on the shore show a faster recovery rate as indicated 


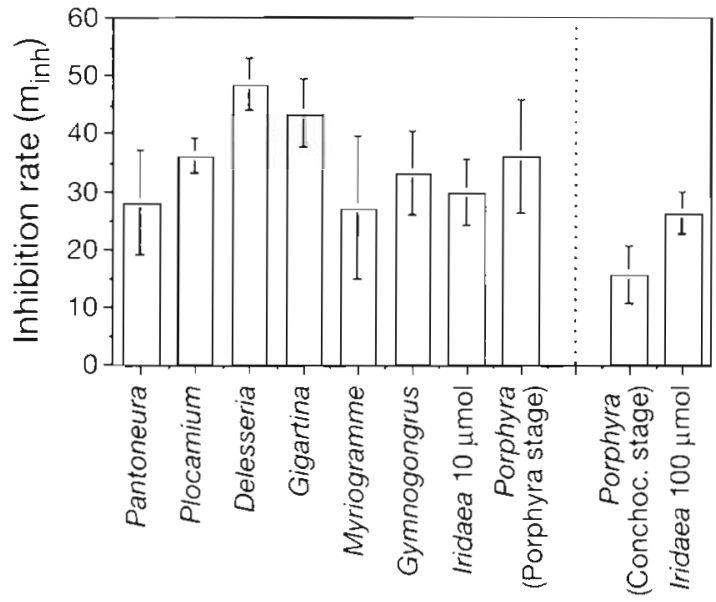

Fig. 7. Inhibition rate $\left(m_{1, n h}\right)$ in relation to the depth distribution of several red algal species. Species are arranged from left to right in relation to their occurrence from the lower subtidal to the intertidal zone. In addition, the reaction of the conchocelis life stage of Porphyra endiviffolium and Iridaea cordata cultured at both 10 and $100 \mu \mathrm{mol} \mathrm{m}^{-2} \mathrm{~s}^{-1}$ are shown $(\mathrm{n}=3$, mean value \pm standard deviation)

by a more negative value (Fig 8 ) There is a statistically significant difference (Fisher's PLSD, $p<0.002$ ) between the upper subtidal group compared to the lower and middle subtidal group (ANOVA, df $=2,25$, $\mathrm{MS}=5705, F=15.5, \mathrm{p}<0.0001$ ). Algae growing at the upper part of the coast recover much faster from photoinhibition than algae from the lower or middle part. Recovery of $I$. cordata was not significantly enhanced by acclimation to a higher irradiance in culture. The conchocelis stage of $P$. endiviifolium showed only a low recovery rate, despite its strong decrease of the photosynthetic efficiency during the inhibition phase.

A comparison of inhibition in brown algae is shown in Fig. 9. The inhibition rate was significantly slower (i.e. higher $m_{\text {inh }}$-value) in the subtidal Himantothallus

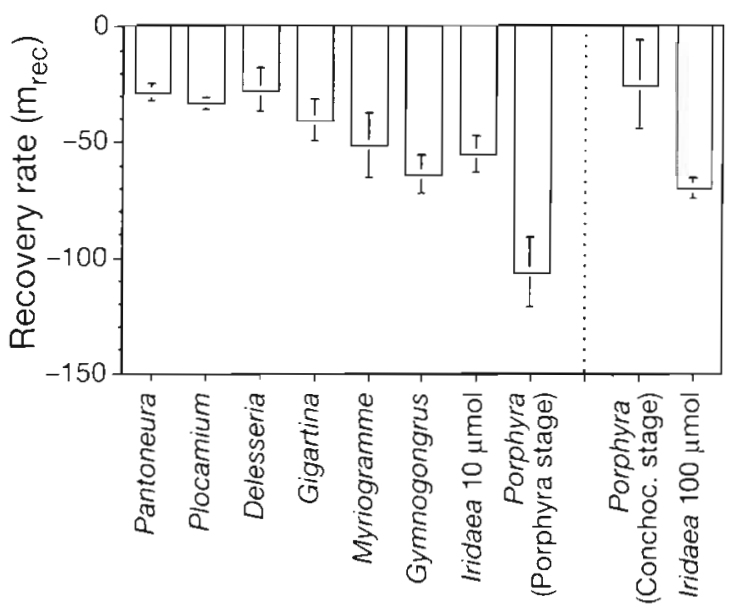

Fig. 8. Recovery rate $\left(m_{\text {rec }}\right)$ of photosynthesis in red algal species after high light stress. Details as in Fig. 7

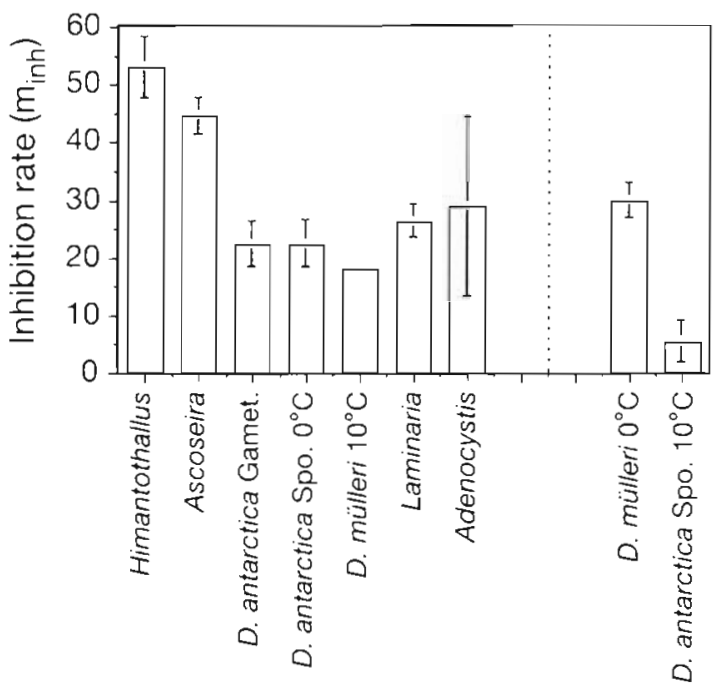

Fig. 9. Inhibition rate $\left(m_{t n k}\right)$ in relation to depth distribution of several brown algal species. Species are arranged from left to right in relation to their occurrence from the lower subtidal to the intertidal zone. In addition, the reactions of Desmarestia mülleri measured at $0^{\circ} \mathrm{C}$ and $D$. antartica at $10^{\circ} \mathrm{C}$ are shown temperatures different from the respective culture conditions ( $\mathrm{n}=3$, mean value \pm standard deviation)

grandifolius and Ascoseira mirabilis compared to the upper subtidal and intertidal species, as already observed in the oxygen measurements. In an additional experiment, Desmarestia mülleri from southern Chile was cultured at $10^{\circ} \mathrm{C}$ and measured at $0^{\circ} \mathrm{C}$. The lower temperature during high light treatment clearly slowed down the inhibition. In contrast, an increase of temperature in Desmarestia antartica, cultured at $0^{\circ} \mathrm{C}$, clearly caused a faster inhibition. The gametophyte of $D$. antartica showed no difference in its reaction to photoinhibition compared to its sporophyte. The re-

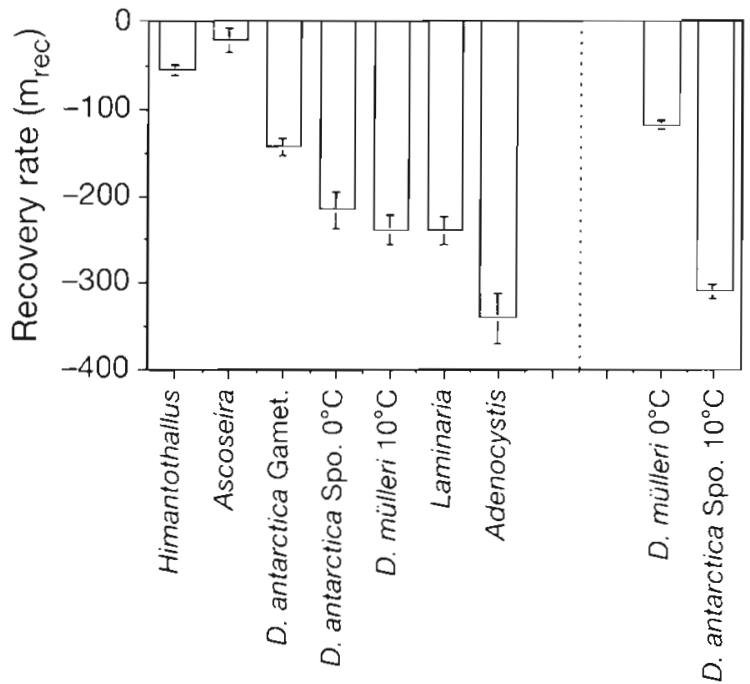

Fig. 10. Recovery rate $\left(m_{\text {rec }}\right)$ of photosynthesis in brown algal species after high light stress. Details as in Fig. 9 
covery kinetics after high light stress was correlated with depth distribution (Fig. 10). The intertidal species Adenocystis utricularis showed the fastest recovery rate, whereas $H$. grandifolius and $A$. mirabilis had the slowest recovery. Recovery of $D$. mülleri was delayed at the lower temperature and the sporophyte of $D$. antartica recovered much faster at the higher temperature and faster than its gametophyte.

\section{DISCUSSION}

Polar algae are not only adapted to low light conditions (Wiencke et al. 1993, Kirst \& Wiencke 1995, Wiencke 1996), but also have the capability to cope with a temporary stress due to high solar radiation during low tide at noon in summer (Hanelt et al. 1993, 1994). Under such excessive irradiance the photosynthetic apparatus is overloaded and the probability of photodamage, caused for example by a higher rate of active oxygen production, increases (Asada \& Takahashi 1987, Demmig-Adams \& Adams 1992. Hanelt 1996). A number of recent investigations showed that photosynthetic activity of marine macroalgae decreases around noon due to the activity of photoprotective mechanisms (cf. Henley 1993, Hanelt 1996). Moreover, UV-radiation at the water surface can aggravate the light stress of photosynthesis (Dring et al. 1996. Häder et al. 1996, Hanelt et al. 1997a). Thus, sublittoral plants have to acclimate to the specific light environment by protective mechanisms, such as dynamic photoinhibition, which causes a harmless dissipation of excessively absorbed energy (Krause \& Weis 1991, Osmond 1994). Herbert \& Waaland (1988) observed that the subtidal Porphyra nereocystis is more rapidly and more strongly photoinhibited than the high light adapted Porphyra perforata growing in the intertidal. The same was found in sunand shade-acclimated thalli of Ulva rotundata (Henley et al. 1991).

The present study indicates that the capability of polar algae to cope with a temporary high light stress is genetically fixed. A fast conversion of xanthophylls could cause a rapid decrease of photosynthetic efficiency, which is also rapidly reversible and may be responsible for the first phase of the recovery process, e.g. in Adenocystis utricularis (Fig. 5B). Similar results have been obtained in spinach by Thiele \& Krause (1996) and in macroalgae by Franklin et al. (1992), Hanelt et al. (1997b) and Rmiki et al. (1996) and were regarded as dynamic photoinhibition (Osmond 1994). A slow recovery rate, which may be caused by slow repair of damaged reaction centre proteins, indicates that e.g. the light sensitive conchocelis stage of Porphyra endivifolium was possibly photodamaged by the high light treatment rather than protected by dynamic photoinhibition.

In the present investigations, oxygen and fluorescence measurements show similar results. However, the correlation of the acclimation potential under high light conditions to the occurrence of the species in the field is stronger in the fluorescence studies. This apparent discrepancy between the 2 methods is caused by the much longer time period necessary to record the P-I curve of oxygen production. Photosynthesis begins to recover from photoinhibition even during the recordings, especially in rapidly reacting species from the intertidal, so the reaction is then underestimated (Hanelt et al. 1992). A clear advantage of the oxygen measurements is that the photosynthetic parameters indicate the activity of the Calvin cycle as well as respiration, whereas the fluorescence parameters indicate only changes in quantum yield and energy transfer in photosystem II.

The differences in the reactions observed between the different algal classes are certainly caused by the different structures of the respective photosynthetic apparatus. Moreover, most of the polar green algal species grow in the upper littoral zone and, hence, are probably adapted to the higher light conditions. A comparison within each class is more informative. Here, it is obvious that photoprotective mechanisms in species from the upper littoral zones have a higher acclimation potential than mechanisms in species from the lower sublittoral. The different ability to tolerate high light stress was not induced by different irradiances in culture and, therefore, must be a genetically fixed adaptation.

Algae growing in the field close to the water surface may not be severely stressed by a fluence rate of $500 \mu \mathrm{mol} \mathrm{m} \mathrm{m}^{-2} \mathrm{~s}^{-1}$ and, hence, generally show no, or only a slight, decrease in $P_{\max }$ or $\alpha$. Nevertheless, the fast changes of the fluorescence ratio during inhibition and at the beginning of the recovery phase showed that photosynthetic efficiency can acclimate very quickly to the new light conditions, especially in these algae.

Algae growing in the middle and upper subtidal zone show a decrease in $P_{\max }$ and $\alpha$ during high light stress but fully recover in the subsequent dim light period. Fluorescence measurements show that the recovery kinetics are slower than in algae normally growing closer to the water surface or in the intertidal algae.

In the lower subtidal high light conditions do not occur. Algae growing in this region also show a decrease in the photosynthetic parameters due to high light stress, but photosynthesis can recover only slightly and very slowly. In these algae the decrease in the photosynthetic activity was probably caused by photo- 
damage rather than by dynamic photoinhibition, which is a rapidly reversible process (Krause \& Weis 1991).

In general, brown algae show faster recovery kinetics than red algae as already observed earlier (Hanelt et al. 1992, 1993, 1994). The intertidal green algae showed the significantly lowest decrease in $P_{\max }$ and $\alpha$ because they are not severely stressed by an irradiance of $500 \mu \mathrm{mol} \mathrm{m}^{-2} \mathrm{~s}^{-1}$

There are 2 exceptions, the red alga Pantoneura plocamioides and the brown alga Ascoseira mirabilis, which do not fit well into our model. $A$. mirabilis recovers too slowly in fluorescence experiments and recovers only slightly in oxygen measurements, contrary to our expectations for a brown algal species growing in the middle and upper subtidal zone (Klöser et al. 1996). One explanation may be that the photoinhibitory response varies in the different parts of the blade in a manner similar to that of photosynthetic parameters (Gómez et al. 1995, 1996). In this study only the oldest distal blade parts were used, which are possibly characterized by low recovery rates. Moreover, in the natural environment the thallus is often overgrown by epiphytes, which shade the thallus. Besides possible effects of long-term culture at low irradiances, these observations could also account for the observed extremely high light sensitivity of A. mirabilis. P. plocamioides shows slow reaction kinetics in the fluorescence measurements, in accordance with the model; however in contrast it shows no significant photoinhibition of oxygen production. A similar discrepancy between oxygen and fluorescence measurements was observed once before in the red marine macroalga Palmaria palmata (Hanelt \& Nultsch 1995) and one reason was the different time resolution of the methods used. More work has to be done here, and also with respect to photoinhibition of carbon fixation. In this respect, Schofield et al. (1995) showed that fluorescence might also overestimate photoinhibition of carbon fixation rates in Antarctic ice algal communities.

The recovery rate of the red alga Iridaea cordata was lower than that of Gymnogongrus antarcticus, although $I$. cordata generally grows in higher parts of the shore. In culture, I. cordata grew only very slowly so that the fluence rate was increased to $100 \mu \mathrm{mol} \mathrm{m} \mathrm{m}^{-2}$ $\mathrm{s}^{-1}$, inducing a higher growth rate. Due to the higher culture irradiance, the mean value of the recovery rates became slightly higher, but this was not significantly different. With the second exception of the Porphyra endiviifolium conchocelis life stage all other species were cultured under the same light conditions so that light acclimation effects can be excluded.

Desmarestia mülleri occurs in southern Chile and does not grow at $0^{\circ} \mathrm{C}$ (Wiencke \& tom Dieck 1990), and thus was cultured at $10^{\circ} \mathrm{C}$. During the experiments a lower temperature $\left(0^{\circ} \mathrm{C}\right)$ significantly slowed the reac- tion kinetics of photoinhibition and recovery in this alga. It is an effect of the enzymatic steps which are involved in photoinhibition and recovery of photosynthesis (Luclow 1987). In support of this, an increase of the experimental temperature from 0 to $10^{\circ} \mathrm{C}$ caused a significant increase of the reaction speed of both processes in $D$. antartica, a species which, however, does not grow at $10^{\circ} \mathrm{C}$ (Wiencke \& tom Dieck 1989). In summary, in the laboratory the temperature showed a strong effect on the reaction kinetics and higher temperatures may be beneficial for the photoprotective process. Antarctic algae growing in shallow waters in the field respond nonetheless with very fast reaction kinetics to light stress at low temperatures (Hanelt et al. 1994).

In conclusion these experiments indicate that algae which are cultured for a long time in the laboratory show still a certain adaptation to the light environment in the habitat. This is valid for the lower light limit (cf. Kirst \& Wiencke 1995) as well as for the upper light limit. Field experiments testing the capability of Arctic algae to cope with temporary high light stress were carried out in summer 1995 in Spitsbergen (Hanelt et al. 1997 a). These results are in clear agreement to the results of our laboratory experiment reported here. However, it should be mentioned that light is only one factor determining the depth distribution of macroalgae. The abiotic factors temperature, salinity, desiccation, $\mathrm{CO}_{2}$ supply and water turbulence, as well as the biotic factors of grazing and competition between the algae, also influence their distribution on the shore (Dring \& Brown 1982, Einav et al. 1995, Klöser et al. 1996).

Acknowledgements. We are indebted to the Deutsche Forschungsgemeinschaft for financial support. Thanks go also to A. Mascher and C. Langreder for the help in culture and technical assistance. Contribution no. 1227 of the Alfred Wegener Institute for Polar and Marine Research.

\section{LITERATURE CITED}

Asada K. Takahashi M (1987) Production and scavenging of active oxygen in photosynthesis. In: Kyle DJ, Osmond $C B$, Arntzen CJ (eds) Photoinhibition. Topics in photosynthesis, Vol 9. Elsevier Science Publishers, Amsterdam, p 89-109

Chapman ARO, Lindley JE (1980) Seasonal growth of Laminaria solidungula in the Canadian High Arctic in relation to irradiance and dissolved nutrient concentrations. Mar Biol 57:1-5

Clayton MN, Wiencke C (1986) Techniques and equipment for culturing Antarctic benthic marine algae, and for preparing specimens for electron microscopy. Ser Cient INACH 34:93-97

Demmig-Adams B, Adams III WW (1992) Photoprotection and other responses of plants to high light stress. Annu Rev Plant Physiol Plant Mol Biol 43:599-626

Drew EA (1974) Light inhibition of photosynthesis in macro- 
algae. Br Phycol J 9:217-218

Dring MJ, Brown FA (1982) Photosynthesis of intertidal brown algae during and after periods of emersion: a renewed search for physiological causes of zonation. Mar Ecol Prog Ser 8:301-308

Dring MJ, Wagner A, Boeskov J, Luning K (1996) Sensitivity of intertidal and subtidal red algae to UVA and UVB radiation. as monitored by chlorophyll fluorescence measurements: influence of collection depth and season, and length of irradiation. Eur J Phycol 31:293-302

Einav R, Breckle S, Beer S (1995) Ecophysiological adaptation strategies of some intertidal marine macroalgae of the Israeli Mediterranean coast. Mar Ecol Prog Ser 125: 219-228

Fortes MD, Lüning K (1980) Growth rates of North Sea macroalgae in relation to temperature, irradiance and photoperiod. Helgoländer Meeresunters 34:15-29

Franklin LA, Levavasseur G. Osmond CB, Henley WJ, Ramus $J$ (1992) Two components of onset and recovery during photoinhibition of Ulva rotundata. Planta 186:399-408

Gómez D, Thomas DN, Wiencke C (1995) Longitudinal profiles of growth, photosynthesis and light independent carbon fixation in the Antarctic brown alga Ascoseira mirabilis. Bot Mar 38:157-164

Gómez D, Wiencke C, Thomas DN (1995) Variations in photosynthetic characteristics of the Antarctic brown alga Ascoseira mirabilis Skottsberg in relation to thallus age and size. Eur J Phycol 31:167-172

Häder DP, Herrmann H, Santas R (1996) Effects of solar radiation and solar radiation deprived of UV-B and total UV on photosynthetic oxygen production and pulse amplitude modulated fluorescence in the brown alga Padina pavonia. FEMS Microbiol Ecol 19:53-61

Hanelt D (1992) Photoinhıbition of photosynthesis in marine macrophytes of the South China Sea. Mar Ecol Prog Ser 82:199-206

Hanelt D (1996) Photoinhibition of photosynthesıs in marine macroalgae. Sci Mar 60(Suppl 1):243-248

Hanelt D, Huppertz K, Nultsch W (1992) Photoinhibition of photosynthesis and its recovery in red algae. Bot Acta 105: $278-284$

Hanelt D, Huppertz K, Nultsch W (1993) Daily course of photosynthesis and photoinhibrtion in marine macroalgae investigated in the laboratory and in the field. Mar Ecol Prog Ser 97:31-71

Hanelt D, Jaramillo MJ, Nultsch W, Senger S, Westermeier R (1994) Photoinhibition as a regulative mechanism of photosynthesis in marine algae of Antarctica. Ser Cient INACH 44:67-77

Hanelt D, Nultsch W (1995) Field studies of photoinhibition show non-correlations between oxygen and fluorescence measurements in the Arctic red alga Palmaria palmata. J Plant Physiol 1.45:31-38

Hanelt D, Uhrmacher S, Nultsch W (1995) The effect of photoinhibition on photosynthetic oxygen production in the brown alga Dictyota dichotoma. Bot Acta 108:99-105

Hanelt D, Wiencke C, Karsten U, Nultsch W (1997a) Photoinhibition and recovery after high light stress in different developmental and life history stages of Laminaria saccharina (Phaeophyta). J Phycol (in press)

Hanelt D, Wiencke C, Nultsch W (1997b) Influence of UV radiation on photosynthesis of Arctic macroalgae in the field. J Photochem Photobiol B: Biology (in press)

Henley W (1993) Measurements and interpretation of photosynthetic light-response curves in algae in the context of photoinhibition and diel changes. J Phycol 29:729-739

Henley WJ, Levavasseur G, Franklin LA, Lindley ST, Ramus J,
Osmond CB (1991) Diurnal responses of photosynthesis and fluorescence in Ulva rotundata acclimated to sun and shade in outdoor culture. Mar Ecol Prog Ser 75:19-28

Herbert SK, Waaland JR (1988) Photoinhibition of photosynthesis in a sun and a shade species of the red algal genus Porphyra. Mar Biol 97:1-7

Huppertz K. Hanelt D, Nultsch W (1990) Photolnhibition of photosynthesis in the marine brown alga Fucus serratus as studied in field experiments. Mar Ecol Prog Ser 66 $175-182$

Kain JM (1969) The blology of Laminaria hyperborea. V Comparison with early stages of competitors. J Mar Biol Assoc UK 49:455-473

Kirst O, Wiencke C (1995) Ecophysology of polar algae. J Phycol 31:181-199

Klöser H, Ferreyra G, Schloss I, Mercuri G, Laturnus F, Curtosi A (1993) Seasonal variation of algal growth conditions in sheltered Antarctic bays: the example of Potter Cove (King George Island, South Shetlands). J Mar Syst 4 : 289-301

Klöser H, Mercuri G, Laturnus F, Quartino ML, Wiencke C (1994) On the competitive balance of macroalgae at Potter Cove (King George Island, South Shetlands). Polar Biol 14:11-16

Klöser H, Quartino ML. Wiencke $C$ (1996) Distribution of macroalgae and macroalgal communities in gradients of physical conditions in Potter Cove, King George Island, Antartica. Hydrobiol 333:1-17

Krause GH, Weis E (1991) Chlorophyll fluorescence and photosynthesis: the basics. Annu Rev Plant Physiol Plant Mol Biol 42:313-349

Larkum AWD, Wood WF (1993) The effect of UV-B radiation on photosynthesis and respiration of phytoplankton, benthic macroalgae and seagrasses. Photosynth Res 36:17-23

Ludlow MM (1987) Light stress at high temperature. In: Kyle DJ, Osmond CB, Arntzen CJ (eds) Photoinhibition. Topics in photosynthesis, Vol 9. Elsevier Science Publishers, Amsterdām, p 89-109

Lüning $\mathrm{K}$ (1990) Seaweeds - their environment, biogeography and ecophysiology. John Wiley \& Sons, New York

Lüning K, Dring MJ (1979) Continuous underwater light measurement near Helgoland (North Sea) and its significance for characteristic light limits in the sublittoral region. Helgoländer Meeresunters 32:403-424

Lüning K, Neushul M (1978) Light and temperature demands for growth and reproduction of laminarian gametophytes in southern and central California. Mar Biol 45:297-309

Osmond CB (1994) What is photoinhibition? Some insights from comparisons of shade and sun plants. In: Baker NR, Bowyer JR (eds) Photomhibition of photosynthesis, from the molecular mechanisms to the field. BIOS Scientific Publ, Oxford, p 1-24

Rmiki NE, Brunet C, Cabioch J, Lemoine Y (1996) Xanthophyll-cycle and photosynthetic adaptation to environment in macro-and microalgae. Hydrobiol 326/327:407-413

Schofield O, Kroon BMA, Prezelin BB (1995) Impact of ultraviolet- $B$ radiation on photosystem II activity and its relationship to the inhibition of carbon fixation rates for antartic ice algae communities. J Phycol 31:703-715

Schreiber U, Schliwa U, Bilger W (1986) Continuous recording of photochemical and non-photochemical chlorophyll fluorescence quenching with a new type of modulation fluorometer. Photosynth Res 10:51-62

Starr RC, Zeikus JA (1987) UTEX-a culture collection of algae at the University of Texas at Austin. J Phycol 23 (suppl):1-47

Thiele A, Krause G (1996) Xanthophyll cycle and thermal 
energy dissipation in photosystem II: relationship between zeaxanthin formation, energy-dependent fluorescence quenching and photolnhibition. J Plant Physiol $144: 324-332$

Wiencke C (1988) Notes on the development of some benthic marine macroalgae of King George Island, Antarctica. Ser Cient INACH 37:23-47

Wiencke C (1990a) Seasonality of brown macroalgae from Antarctica-a long-term culture study under fluctuating Antarctic daylengths. Polar Biol 10:589-600

Wiencke C (1990b) Seasonality of red and green macroalgae from Antarctica - a long-term culture study under fluctuating Antarctic daylengths. Polar Biol 10:601-607

Wiencke C (1996) Recent advances in the investigation of

This article was submitted to the editor
Antarctic macroalgae. Polar Biol 16:231-240

Wiencke C. Fischer G (1990) Growth and stable carbon isotope composition of cold-water macroalgae in relation to light and temperature. Mar Ecol Prog Ser 65:283-292

Wiencke C, Rahmel J, Karsten U, Weykam G, Kirst GO (1993) Photosynthesis of marine macroalgae from Antarctica: light and temperature requirements. Bot Acta 106:78-87

Wiencke C, tom Dieck I (1989) Temperature requirements for growth and temperature tolerance of macroalgae endemic to the Antarctic region. Mar Ecol Prog Ser 54:189-197

Wiencke C, tom Dieck I (1990) Temperature requirements for growth and survival of macroalgae from Antarctica and Southern Chile. Mar Ecol Prog Ser 59:157-170

Manuscript first received: December 19, 1996 Revised version accepted: February 25, 1997 